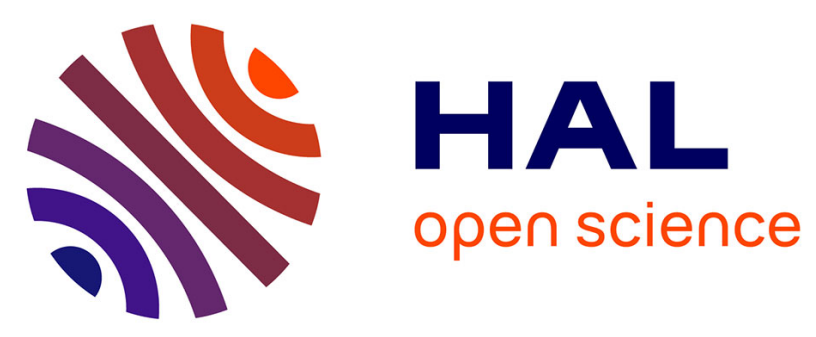

\title{
The influence of wearing compression stockings on performance indicators and physiological responses following a prolonged trail running exercise
}

Christophe Hausswirth, Fabrice Vercruyssen, Christopher Easthope, Thierry Bernard, François Bieuzen, Mathieu Gruet, Jeanick Brisswalter

\section{To cite this version:}

Christophe Hausswirth, Fabrice Vercruyssen, Christopher Easthope, Thierry Bernard, François Bieuzen, et al.. The influence of wearing compression stockings on performance indicators and physiological responses following a prolonged trail running exercise. European Journal of Sport Science, 2012, 14 (2), pp.144-150. 10.1080/17461391.2012.730062 . hal-01835207

\section{HAL Id: hal-01835207 \\ https: / hal-insep.archives-ouvertes.fr/hal-01835207}

Submitted on 11 Jul 2018

HAL is a multi-disciplinary open access archive for the deposit and dissemination of scientific research documents, whether they are published or not. The documents may come from teaching and research institutions in France or abroad, or from public or private research centers.
L'archive ouverte pluridisciplinaire HAL, est destinée au dépôt et à la diffusion de documents scientifiques de niveau recherche, publiés ou non, émanant des établissements d'enseignement et de recherche français ou étrangers, des laboratoires publics ou privés. 
The influence of wearing compression stockings on performance indicators and physiological responses following a prolonged trail running exercise

Fabrice Vercruyssen ${ }^{\text {a }}$, Christopher Easthope ${ }^{\text {a }}$, Thierry Bernard ${ }^{\text {a }}$, Christophe Hausswirth ${ }^{\text {b }}$ François Bieuzen ${ }^{\mathrm{b}}$, Mathieu Gruet ${ }^{\mathrm{a}} \&$ Jeanick Brisswalter ${ }^{\mathrm{a}}$

\author{
a UFR STAPS, LAHMESS, Nice Sophia Antipolis, Nice, France \\ b INSEP, Paris, France \\ Correspondence: F. Vercruyssen, STAPS, LAHMESS, Nice Sophia Antipolis, Nice 06000, France. \\ E-mail: vercruyssen@univ-tln.fr
}

Article publié dans : European Journal of Sport Science ISSN 1746-1391 DOI: 10.1080/17461391.2012.730062 (iFirst 16 Octobre 2012)

\begin{abstract}
The objective of this study was to investigate the effects of wearing compression socks (CS) on performance indicators and physiological responses during prolonged trail running. Eleven trained runners completed a $15.6 \mathrm{~km}$ trail run at a competition intensity whilst wearing or not wearing CS. Counter movement jump, maximal voluntary contraction and the oxygenation profile of vastus lateralis muscle using near-infrared spectroscopy (NIRS) method were measured before and following exercise. Run time, heart rate (HR), blood lactate concentration and ratings of perceived exertion were evaluated during the CS and non-CS sessions. No significant difference in any dependent variables was observed during the run sessions. Run times were $5681.1 \pm 503.5$ and $5696.7 \pm 530.7 \mathrm{~s}$ for the non-CS and CS conditions, respectively. The relative intensity during CS and non-CS runs corresponded to a range of 90.5-91.5\% HRmax. Although NIRS measurements such as muscle oxygen uptake and muscle blood flow significantly increased following exercise $(+57.7 \%$ and + $42.6 \%,+59.2 \%$ and $+32.4 \%$, respectively for the CS and non-CS sessions, $\mathrm{P}<0.05$ ), there was no difference between the run conditions. The findings suggest that competitive runners do not gain any practical or physiological benefits from wearing CS during prolonged off-road running.
\end{abstract}

Keywords: Compression socks, trail running, performance indicators, muscle oxygenation, physiological responses 


\section{Introduction}

During the two last decades, road runners have been wearing compression garments (CGs) during race particularly with the use of compression socks (CS) in an attempt to enhance their performance (e.g. Paula Radcliffe, Lornah Kiplagat). Since the intensive development of technological clothing in the area of endurance sports, the wearing of CS has been widely used by on and off-road runners for training and racing. Based on anecdotal reports, runners often comment on their leg's feeling with a lower perception of strain in the calf when exercising with CS. These statements are in line with a previous study indicating that kneelength CGs are more comfortable with less possibilities of wrinkling when compared to thighlength CGs (Benkö, Cooke, McNally, \& Mollan, 2001). Paradoxically, a lack of clear evidence of CS benefits was reported for performance, indicators of muscle power (e.g. countermovement jump) or metabolic adaptations in trained runners (Ali, Creasy, \& Edge, 2011; Goh, Laursen, Dascombe, \& Nosaka, 2011; Ménétrier, Mourot, Bouhaddi, Regnard, \& Tordi, 2011; Sperlich et al., 2010, 2011; Varela-Sanz, Espana, Carr, Boullosa, \& EsteveLanao, 2011). However, little is known about the analysis of selected physiological variables (e.g. muscle oxygenation) and performance responses (e.g. maximal voluntary contraction [MVC]) following a prolonged running exercise $(>1-\mathrm{h})$ close to the race intensity. Interestingly, using near-infrared spectroscopy (NIRS) method, Dascombe, Hoare, Sear, Reaburn, and Scanlan (2011) have demonstrated that wearing CGs positively influenced a number of peripheral circulatory measures within the vastus lateralis (VL) during a time to exhaustion conducted at a competition pace in runners. However, these peripheral physiological benefits were not correlated to a significant improvement in running performance. Similarly, Varela-Sanz et al. (2011) have recently reported a non-significant increase of approximately $13 \%$ in time limit running test under CS condition, at a competitive velocity. Although the small number of subjects $(n=6)$ might partly explain the lack of significant differences between CS and non-CS conditions, these investigators showed a cardiac benefit in runners wearing CS, resulting in a significant decrease in relative intensity (i.e. maximal heart rate) sustained during the time limit.

Even if physiological benefits from the wearing of CGs were identified during endurance running performance, it is likely that the exercise duration reported in these recent running studies was not sufficient to highlight any possible benefits of wearing CS on performance responses. Other methodological limitations may be considered in the previous investigations, including not only the use of a treadmill that can potentially change the normal running kinematics and the subsequent energetic requirements of high-intensity endurance running (Wank, Frick, \& Schmidtbleicher, 1998), but also the use of a running time to exhaustion as performance indicator, which may modify pacing strategies related to race performance. Finally, no running analysis has been conducted on the relationship between any form of CGs and performance responses throughout off-road exercises, so-called trail-running, including uphill and downhill sections. In contrast with flat road, the muscular contractions induced during trail-running are specific and dictated by the occurrence of a strong concentric modality during uphill section and a dominant eccentric regimen to downhill section. This 
running exercise might result in higher muscle oscillations and variations in physiological responses, particularly during the repeated downhill sections (Millet et al., 2011).

In contrast with most of laboratory settings, the evaluation of selected metabolic and/or muscular variables remains specific in the outdoor context and requires a serie of measurements conducted before and following exercises (e.g. Easthope et al., 2010; Millet et al., 2011; Sultana et al., 2012). Therefore, the objective of the current study was to examine the effect of a new non-graduated $\mathrm{CS}(18 \mathrm{mmHg})$ on physiological responses and performance indicators following prolonged trail running in experienced off-road runners. Considering the findings reported in the CGs running investigations and also, the specificity of our running task, it may be hypothesised that the physiological benefits of wearing CS (e.g. improved muscle oxygenation, decreased HR response) appear more accentuated during trail running $(\sim 1.5 \mathrm{~h})$ at a competition pace, improving thus performance indicators and physiological responses following prolonged exercise.

\section{Methods}

\section{Subjects}

Eleven male trained runners [(mean $\pm \mathrm{SD})$ age: $34.7 \pm 9.8$ years; height: $178.4 \pm 7.0 \mathrm{~cm}$; body mass: $72.3 \pm 6.8 \mathrm{~kg}$ ] participated to this study after medical examination. All subjects had a minimum of three consistent years of trail running experience over different race distances (from 20 to $80 \mathrm{~km}$ ). Run training time ranged from 8 to $12 \mathrm{~h} \mathrm{wk}-1$, interspersed with competitive events. All subjects gave their informed written consent to participate in the current study, which has been conducted according to the Declaration of Helsinki. A local ethics committee for the protection of individuals gave approval concerning the project before its initiation.

\section{Experimental design}

An overview of the experiment is given in Figure 1. All subjects completed both laboratory and field sessions. At the initial laboratory session, participants performed an incremental exercise test to exhaustion on a motorised treadmill. Pulmonary gas exchanges were collected breath-by-breath and averaged for every $10 \mathrm{~s}$ period using a metabolic measurement system (Oxycon Alpha ${ }^{\circledR}$, Jaeger). The system was calibrated prior to each exercise test according to the manufacturer's instructions. After 6 min of warm-up exercise at $10 \mathrm{~km} \mathrm{~h}-1$, the treadmill speed was increased by $1 \mathrm{~km} \mathrm{~h}-1$ every 2 min (with a 4\% grade). This maximal session did allow to determine mean values in maximal oxygen uptake $\left(\mathrm{VO}_{2 \max }\right)$, maximal ventilation $\left(\mathrm{VE}_{\max }\right)$ and maximal heart rate (HRmax). During laboratory and field testing sessions, HR values were monitored using a polar unit (RS800CX, Polar ${ }^{\circledR}$, Kempele, Finland). During the first visit, particular attention was paid to familiarise participants with the experimental procedures, especially the completion of MVC and counter movement jump (CMJ) to quantify indicators of muscle power.

Subsequently, to familiarise the participants with the experimental off-road sessions, two practice runs were completed on the course. The second run was entirely conducted at a pace 
closer to the race context. The subjects were habitual users of CS during training and racing, avoiding potential discomfort in the calf area. Likewise, red markers were placed on the ground every $200 \mathrm{~m}$ to facilitate the displacement of our runners during the course. These runs were performed between two and four weeks before the experimental runs. After a standard and controlled warm-up of $10 \mathrm{~min}$, the off-road sessions consisted of completing two maximal (race effort) $15.6 \mathrm{~km}$ trail runs, in a random order, on two separate days one week apart, wearing CS or not wearing CS (non-CS). Runners were asked to wear the same shoes and the similar clothing (without thigh compression) for CS and non-CS conditions. For the CS session, subjects wore socks extending from below the knee to the lateral malleolus (constant pressure of $18 \mathrm{mmHg}$ applied to the calf/94\% Polyamide and 6\% Lycra). During the first run, subjects consumed carbohydrate $(\mathrm{CHO})$ in the form of gel $(25 \mathrm{~g}$, two per runner) and energy drinks $(6 \% \mathrm{CHO} / 600 \mathrm{ml}$ of water per runner). Fluid intake was measured by weighing the bottle after the first run on an electronic scale (accurate to $1 \mathrm{~g}$ ). Subsequently, the quantity of ingested $\mathrm{CHO}$ gels and fluid intake was individually replicated during the second run. Finally, the runners were separated to avoid pacing strategies or psychological impact affecting run time. Likewise, the day before each trial, the runners were asked to refrain from strenuous exercise and they were also asked to keep the same nutritional routine before each trial, with the same breakfast at the same time, similar to what they would do before a race.

More precisely, the $15.6 \mathrm{~km}$ trail-running consisted of the completion of three $5.2 \mathrm{~km}$ loops with a brief rest period of $40 \mathrm{~s}$ fixed between the loops for data collection (Figure 1). Each loop was divided into two sections completed systematically in the following order: uphill $(2200 \mathrm{~m})$ and downhill section $(3000 \mathrm{~m})$ with average gradients of 13\% and $9 \%$, respectively. The positive elevation was $275 \mathrm{~m}$ for each loop. The profile of trail-running was characterised by the completion of $100 \%$ single tracks in the mountain and repeated technical portions with rocky/root filled paths. Weather conditions were stable with ambient temperatures ranging from 20 to $24^{\circ} \mathrm{C}$ (South of France) during the sessions.

\section{Measurements during CS and non-CS sessions}

During the 40 s rest periods fixed between the loops of CS and non-CS sessions (Figure 1), the ratings of perceived exertion (RPE) scale using the Borg 6-20 was presented to the subjects who was asked to say the number that reflected the perceived exertion for (1) an 'overall' or total body rating (RPEglobal), (2) a central or 'heart/lungs' rating (RPEcentral) and (3) a peripheral or 'legs' rating (RPEperipheral; Borg, 1998). Moreover, the blood lactate concentration [Bla-] was obtained using a Lactate Pro ${ }^{\circledR}$ analyser (Akray, Kyoto, Japan) from $5 \mu \mathrm{L}$ samples of blood taken from the earlobe during the rest periods of CS and non-CS runs. Athletes were also equipped with a RS800CX G3 (Polar ${ }^{\circledR}$, Kempele, Finland) including a GPS receiver fixed on the arm for monitoring HR and displacement values.

\section{Measurements before and following CS and non-CS sessions}

\section{Near-infrared spectroscopy measurements}

Oxygenation profile of the right VL muscle was recorded using a continuous-wave NIRS system (PortaMon®; Artinis Medical Systems BV, Zetten, the Netherlands). This analysis 
was conducted prior to the warm-up of run sessions and following CS and non-CS bouts $(\sim 5$ $\mathrm{min})$ to monitor concentration changes in oxyhemoglobin $(\mathrm{HbO} 2)$, deoxyhemoglobin $(\mathrm{HHb})$ and total hemoglobin $(\mathrm{tHb})$. A probe was attached to the middle part of the VL muscle (15-20 $\mathrm{cm}$ above the centre of patella) longitudinally. Pulsed light was emitted from the emission of a three-segment photodiode at two different wavelengths $(760$ and $850 \mathrm{~nm})$ and was detected, as a function of distance, using a photodiode detection probe that received NIRS signals at 2 Hz. To prevent variations in placement of the NIRS emitter-detector, the angle and location of the probe were held constant using Velcro straps. Similarly, the position of the NIRS probe was noted with a marker to ensure identical placement on each subject for all testing sessions. Finally, a light-impermeable cloth covered the probe to reduce room light interaction with the near-infrared signal. Before placement on the VL, the site was shaved and cleaned using alcohol swab. Subjects lay supine in a horizontal position with slightly inclined upper body $\left(15^{\circ}\right)$ keeping their arms at their sides for the duration of the test. In order to determine muscular oxygen uptake $\left(\mathrm{mVO}_{2}\right)$ and blood flow $(\mathrm{mBF})$, two venous occlusions were applied above the belly of the VL (compression of femoral artery), using air inflated to $70 \mathrm{mmHg}$, each lasting $20 \mathrm{~s}$ with a 2 min recovery interval (Ahmadi, Sinclair, \& Davis, 2008a; Ahmadi, Sinclair, Foroughi, \& Davis, 2008b). The medium time-derivative of $\mathrm{HHb}, \mathrm{HbO} 2$ and $\mathrm{tHb}$ was determined over a time period of $20 \mathrm{~s}$ beginning once the pressure of $70 \mathrm{mmHg}$ was reached. Given that the venous outflow was blocked, the initial linear increase in $\mathrm{HHb}$ was used to calculate $\mathrm{mVO}_{2}$ (in $\mathrm{ml} \mathrm{O} 2$ min-1 $100 \mathrm{~g}$ ) (Van Beekvelt, Colier, Wevers, \& Van Engelen, 2001). Moreover, mBF was measured during venous occlusion by evaluating the linear increase in $\mathrm{tHb}$ during the time period of $20 \mathrm{~s}$. Given that the venous outflow was blocked, the increase in $\mathrm{tHb}(\mathrm{HbO} 2+\mathrm{HHb})$ was directly related to the arterial inflow (in $\mathrm{ml} \mathrm{O} 2$ min-1 100 g) (Van Beekvelt et al., 2001). During the pre/post-bouts, $\mathrm{mVO}_{2}$ and $\mathrm{mBF}$ were calculated as the average obtained from the two venous occlusions.

\section{Maximal voluntary contraction}

Instantaneous isometric torque at the knee joint was recorded using a Biodex ${ }^{\circledR}$ isokinetic dynamometer (Shirley, NY). Subjects were placed in a seated position and were securely strapped into the test chair. Extraneous movement of the upper body was limited by two crossover shoulder harnesses and a belt across the abdomen. All measurements were taken before (after a standard warm-up) and $45 \mathrm{~min}$ after the CS and non-CS run sessions from the subject's right leg, with the knee and hip flexed at $90^{\circ}$ from full extension. Subjects were then asked to perform three trials of MVC (4-5 s) with a rest period of $60 \mathrm{~s}$ between each MVC. The highest MVC value of trials was used.

\section{Countermovement jump}

Participants were instructed to adopt a standing position with hands on hips. This position was held for $3 \mathrm{~s}$ before the completion of a maximal vertical jump. Volunteers were instructed to keep their hands on their hips throughout the jump, and their legs straight whilst in the air. Participants stood fully erect, and following a verbal command, initiated a countermovement followed by a maximal vertical jump in one continuous motion. Before and immediately after the run sessions $(\sim 1 \mathrm{~min})$, CMJ heights (in $\mathrm{cm}$ ) were recorded from the Bosco test that 
consists of measuring the flight time with a digital timer $( \pm 0.001 \mathrm{~s}$; Bosco, Luhtanen, \& Komi, 1983). The highest CMJ value of three jumps was used.

\section{Statistical analysis}

Data are presented as mean \pm SD. The Kolmogorov-Smirnov test was applied to ensure a Gaussian distribution of the data. The performance and physiological responses throughout CS and non-CS runs between the pre- and post-periods of each condition were compared by using paired t-tests. For this analysis, the NIRS data expressed as the delta between the pre/post-periods (\%) were evaluated by an arcsine transformation. Furthermore, a 2 (condition) $\times 3$ (time) repeated-measures analysis of variance was used to examine the effects of trail-running sessions on dependent variables within the three loops of exercise. A Tukey post hoc test was used to determine significant differences among CS and non-CS conditions. Statistical significance was accepted at $\mathrm{P}<0.05$.

\section{Results}

For the incremental run exercise, mean values in $\mathrm{VO}_{2 \max }, \mathrm{HRmax}, \mathrm{VE}_{\max }$ were $4.32 \pm 0.43 \mathrm{~L}$ min-1 $(60.1 \pm 6.5 \mathrm{ml} \mathrm{kg}-1 \mathrm{~min}-1), 183 \pm 10$ beats $\min -1$ and $142.4 \pm 20.5 \mathrm{~L}$ min-1, respectively. The analysis of the three loops indicated no significant change in run times $(\sim 2.5 \%$, Figure 2$)$ between the non-CS and CS conditions. The average finishing time of our subjects was $5681.1 \pm 503.5$ and $5696.7 \pm 530.7 \mathrm{~s}$ for the non-CS and CS runs, respectively. The evaluation of isolated run indicated that the mean values in run time for the loop \#1 were significantly lower as compared to those reported for the loops \#2 (-6.10\% only for the CS run, $\mathrm{P}<0.05$, Figure 2$)$ and $\# 3(-9.95 \%$ and $-8.60 \%$, respectively, for the non-CS and CS runs, $\mathrm{P}<0.05$, Figure 2). No significant variation in $\left[\mathrm{Bla}^{-}\right]$and $\mathrm{HR}$ values was observed throughout the loops and between the run sessions (Table I). Moreover, mean values in RPEgloblal, RPEcentral and RPEperipheral were significantly higher during the loop\#3 compared to those reported during the loop\#1 $(\mathrm{P}<0.05)$, without any significant differences between the CS and the non-CS runs. The analysis of the pre/post-measurements indicated significant higher values in $\mathrm{mVO}_{2}$ and $\mathrm{mBF}$ during the post-run, characterised by significant values in $\Delta \mathrm{mVO}_{2}$ and $\triangle \mathrm{mBF}$ (Figure $3, \mathrm{P}<0.05$ ) for the two trail-running sessions. No significant variations in MVC and CMJ were observed following run sessions (212 \pm 45 vs. $214 \pm 55 \mathrm{Nm}, 35 \pm 6$ vs. $32 \pm 5 \mathrm{~cm}$, respectively, for the non-CS and CS conditions).

\section{Discussion}

The originality of our experimental setting was based on a holistic analysis focusing on the use of CS within actual off-road running conditions in trained trail runners $\left(\mathrm{VO} 2_{\max }>60 \mathrm{ml}\right.$ $\mathrm{O} 2 \mathrm{~min}-1 \mathrm{~kg}-1$ ). In contrast with our experimental hypothesis, the main finding of this work was that wearing CS did not have an effect on physiological variables and performance indicators measured during and following prolonged exercise.

The use of CS is increasingly widespread in the domain of trail running ( $>50 \%$ of engaged racers on average, unpublished data), independent of performance level or race distances. However, the practical interest of wearing CS in the running activity under actual racing 
conditions has received little supporting scientific evidence. Most of identified investigations focusing on the use of CGs during running performance have selected either outdoor flat exercises (not exceeding $10 \mathrm{~km}$ or $45 \mathrm{~min}$ ) or time to exhaustion exercises as performance indicator (Ali et al., 2011; Dascombe et al., 2011; Goh et al., 2011; Ménétrier et al., 2011; Sperlich et al., 2010; Varela-Sanz et al., 2011). The present investigation is the first to report performance data in relation with the wearing of CGs following prolonged running $(>1-h)$. However, our findings indicate a lack of significant differences in run times between the CS and non-CS session. Interestingly, our athletes adopted a positive pacing strategy (e.g. Stearns et al., 2009) during which the average speed gradually decreases over the duration of CS and non-CS runs (Figure 2), suggesting that the use of CS has no effect on external factors potentially involved in the pacing strategy. All participants reported a similar effort for each loop of CS and non-CS runs, characterised by a lack of RPE variations between conditions (Table I). The perceptual scales provide a reflection of subjective intensity and, coupled with the physiological measures such as HR, the relevant information is that our runners have performed trail running exercises (across the loops) at the same and high intensity (i.e. $>90 \%$ HRmax). Our results are consistent with recent studies that showed a lack of change in running performance with the use of CS (Ali et al., 2011; Dascombe et al., 2011; Goh et al., 2011; Ménétrier et al., 2011; Sperlich et al., 2010; Varela-Sanz et al., 2011), suggesting that wearing CS (graduated or non-graduated) has no ergogenic effect during various running tasks. Thus, future research is required to analyse the effects of wearing CGs during off-road running exceeding two hours of exercise, especially when fatigue process, muscular damage or muscle oscillations are particularly accentuated (Millet, Martin, Lattier, \& Ballay, 2003; Millet et al., 2011).

During endurance cycling and running exercises, the oxygenation profile has often been investigated from in situ measurements based on the variations in tissue oxygenation index, $\mathrm{HHb}$ or HbO2 (Dascombe et al., 2011; Scanlan, Dascombe, Reaburn, \& Osborne, 2008). These investigations have demonstrated that wearing CGs improved muscle oxygenation without any significant variation in performance response. Alternatively, other NIRS parameters such as $\mathrm{mVO}_{2}$ and $\mathrm{mBF}$ may be used to quantify the muscle oxygenation responses following exercises (Ahmadi et al., 2008a, 2008b). Based on the principle of venous occlusion, these authors have monitored muscle oxygenation using $\mathrm{mVO}_{2}$ and $\mathrm{mBF}$ parameters before and following eccentric exercise-induced muscle damage. Considering this recent method, the present study is the first to report on the variations in $\mathrm{mVO}_{2}$ and $\mathrm{mBF}$ before and following prolonged endurance exercise. The choice of measurement periods (pre/post) was essentially linked to the complexity of analysing physiological parameters during trail running.

In contrast to earlier studies (Dascombe et al. 2011; Ménétrier et al., 2011; Scanlan et al., 2008), no significant variation in NIRS parameters was identified between CS and non-CS runs (Figure 3). The absence of change in oxygenation profile between run sessions might have been influenced by the position of the NIRS probe on the VL whereas the compression level was applied to the calf. This suggests that (1) wearing CS during exercise has no effect on measured systemic $\mathrm{mBF}$ (i.e. effect of $\mathrm{CS}$ on $\mathrm{mBF}$ in the VL) following exercise and that 
(2) the potential benefits of CS on circulatory responses may be expected locally on the compressed muscle region and thus, depend on the amplitude of the myogenic response generated by external compression (Bochmann et al., 2005). Furthermore, $\mathrm{mBF}$ and $\mathrm{mVO}_{2}$ reported in the present work were significantly higher following both CS and non-CS runs when compared to the resting values. The immediate increments in after run sessions might result simply in the increased $\mathrm{mBF}$ to the exercise limbs. In fact, during exercise, the vascular portion of actives muscles is considerably increased by the dilatation of local arterioles. This hyperaemic reaction could be observed after all types of exercise and thus, an increase in $\mathrm{mBF}$ and $\mathrm{mVO}_{2}$ would be an expected finding following any type of exercise (Ahmadi et al., 2008a, 2008b). Alternatively, it has been acknowledged that HR may be used as an indirect measure of venous return and/or circulatory flow, according to the Frank-Starling mechanism (Ali, Caine, \& Snow, 2007; Varela-Sanz et al., 2011). In this regard, the lack of change in HR values across the three loops of CS and non-CS runs suggests that wearing CS does not influence venous return (and oxygenation profile) during exercise and strengthens our finding concerning the NIRS responses obtained immediately after running.

Moreover, the non-significant modification in [Bla-] values among the three loops of CS and non-CS runs (Table I) does not support the claim purported by many CS manufacturers about the improved removal of blood lactate during exercise. The present study also demonstrates that wearing CS during off-road running exercise does not alter selected indicators of muscle power such as CMJ and MVC. For instance, mean CMJ values were well maintained in the CS and non-CS post-runs and may have been due to the 'warm-up' effect. This is in agreement with previous running studies indicating no changes in CMJ values between CS and non-CS conditions (Ali et al., 2007, 2011; Jakeman, Byrne, \& Eston, 2010). Similarly, muscle power characterised by MVC results indicated no significant strength loss when analysing the pre- and post-periods of CS and non-CS runs. Muscle fatigue is often defined as a reduction in the maximum force (i.e. MVC) that a muscle can exert (Millet et al., 2003). Considering this statement, we suggest that despite the specificity of trail running, the exercise duration may be not long enough to induce muscle fatigue in our trained runners. Recently, Ross, Goodall, Stevens, and Harris (2010) have shown the occurrence of knee extensor MVC decrement only during the final $5 \mathrm{~km}$ of a high-intensity $20 \mathrm{~km}$ self-paced run, corresponding approximately to the finishing times ( $\sim 90 \mathrm{~min})$ observed in our study. However, these authors have reported that the MVC was not significantly different from preexercise values after 20 or $40 \mathrm{~min}$ of rest following running exercise. Based on this issue, the lack of strength loss in our study may also be attributed to the time at which the MVC was evaluated (45 $\mathrm{min}$ after the end of exercise).

In conclusion, this is the first investigation that examines the effects of wearing non-graduated CS on performance indicators and selected physiological variables following a prolonged trail running exercise. However, it was demonstrated that competitive runners did not gain any physiological benefits and ergogenic aid from wearing CS during off-road running conducted at a race intensity. Although our results confirm a number of scientific data related to the absence of ergogenic aid under any form of wearing CGs during short running distances $(<90$ $\mathrm{min}$ ), a further topic would be relevant to analyse the impact that different level of exercise 
duration ( $>2-h)$, possibly inducing specific muscle fatigue and associated damage, may have on running performance and physiological responses.

\section{Acknowledgements}

We would like to sincerely thank all participants involved in this study and the research assistants for the data collection and their personal time taken during the overall experiment to optimise experimental sessions; without their efforts this research would not possible. The authors declare that the experiments comply with the current laws of our country in which they were performed.

\section{References}

1. Ahmadi, S., Sinclair, P. J. and Davis, G. M. 2008a. Muscle oxygenation after downhill walking-induced muscle damage. Clinical Physiology and Functional Imaging, 28: 55-63.

2. Ahmadi, S., Sinclair, P. J., Foroughi, N. and Davis, G. M. 2008b. Monitoring muscle oxygenation after eccentric exercise-induced muscle damage using near-infrared spectroscopy. Applied Physiology, Nutrition and Metabolism, 33: 743-752.

3. Ali, A., Caine, M. P. and Snow, B. G. 2007. Graduated compression stockings: Physiological and perceptual responses during and after exercise. Journal of Sports Sciences, 25: 413-419.

4. Ali, A., Creasy, R. H. and Edge, J. A. 2011. The effect of graduated compression stockings on running performance. Journal of Strength and Conditioning Research, 25: 1385-1392.

5. Benkö, T., Cooke, E. A., McNally, M. A. and Mollan, R. A. B. 2001. Graduated compression stockings: Knee length or thigh length. Clinical Orthopaedics and Related Research, 383: 197-203.

6. Bochmann, R. P., Seibel, W., Haase, E., Hietschold, V., Rödel, H. and Deussen, A. 2005. External compression increases forearm perfusion. Journal of Applied Physiology, 99: 23372344.

7. Borg, G. 1998. Borg's perceived exertion and pain scales, Champaign, IL: Human Kinetics.

8. Bosco, C., Luhtanen, P. and Komi, P. V. 1983. A simple method for measurement of mechanical power in jumping. European Journal of Applied Physiology, 50: 273-282.

9. Dascombe, B. J., Hoare, T. K., Sear, J. A., Reaburn, P. R. and Scanlan, A. T. 2011. The effects of wearing undersized lower-body compression garments on endurance running performance. International Journal of Sports Physiology and Performance, 6: 160-173.

10. Easthope, C. S., Hausswirth, C., Louis, J., Lepers, R., Vercruyssen, F. and Brisswalter, J. 2010. Effects of a trail running competition on muscular performance and efficiency in welltrained young and master athletes. European Journal of Applied Physiology, 110: 1107-1116. 
11. Goh, S., Laursen, P. B., Dascombe, B. and Nosaka, K. 2011. Effect of lower body compression garments on submaximal and maximal running performance in cold $\left(10^{\circ} \mathrm{C}\right)$ and hot $\left(32^{\circ} \mathrm{C}\right)$ environments. European Journal of Applied Physiology, 111: 819-826.

12. Jakeman, J. R., Byrne, C. and Eston, R. G. 2010. Lower limb compression garment improves recovery from exercise-induced muscle damage in young, active females. European Journal of Applied Physiology, 109: 1137-1144.

13. Ménétrier, A., Mourot, L., Bouhaddi, M., Regnard, J. and Tordi, N. 2011. Compression sleeves increase tissue oxygen saturation but not running performance. International Journal of Sports Medicine, 32: 864-868.

14. Millet, G. Y., Martin, V., Lattier, G. and Ballay, Y. 2003. Mechanisms contributing to knee extensor strength loss after prolonged running exercise. Journal of Applied Physiology, 94: 193-198.

15. Millet, G. Y., Tomazin, K., Verges, S., Vincent, C., Bonnefoy, R.Boisson, R. C. 2011. Neuromuscular consequences of an extreme mountain ultra-marathon. PLoS One, 6: e17059

16. Ross, E. Z., Goodall, S., Stevens, A. and Harris, I. 2010. Time course of neuromuscular changes during running in well-trained subjects. Medicine and Science in Sports and Exercise, 42: 1184-1190.

17. Scanlan, A. T., Dascombe, B. J., Reaburn, P. R. and Osborne, M. 2008. The effects of wearing lower-body compression garments during endurance cycling. International Journal of Sports Physiology and Performance, 3: 424-438.

18. Sperlich, B., Haegele, M., Achtzehn, S., Linville, J., Holmberg, H. C. and Mester, J. 2010. Different types of compression clothing do not increase sub-maximal and maximal endurance performance in well-trained athletes. Journal of Sports Sciences, 28: 609-614.

19. Sperlich, B., Haegele, M., Krüger, M., Schiffer, T., Holmberg, H. C. and Mester, J. 2011. Cardio-respiratory and metabolic responses to different levels of compression during submaximal exercise. Phlebology, 26: 102-106.

20. Stearns, R. L., Casa, D. J., Lopez, R. M., McDermott, B. P., Ganio, M. S.Decher, N. R. 2009. Influence of hydration status on pacing during trail running in the heat. Journal of Strength and Conditioning Research, 23: 2533-2541.

21. Sultana, F., Abbiss, C. R., Louis, J., Bernard, T., Hausswirth, C. and Brisswalter, J. 2012. Age-related changes in cardio-respiratory responses and muscular performance following an Olympic triathlon in well-trained triathletes. European Journal of Applied Physiology, 112: $1549-1556$.

22. Van Beekvelt, M. C., Colier, W. N., Wevers, R. A. and Van Engelen, B. G. 2001. Performance of near-infrared spectroscopy in measuring local $\mathrm{O} 2$ consumption and blood flow in skeletal muscle. Journal of Applied Physiology, 90: 511-519. 
23. Varela-Sanz, A., Espana, J., Carr, N., Boullosa, D. A. and Esteve-Lanao, J. 2011. Effects of gradual-elastic compression stockings on running economy, kinematics, and performance in runners. Journal of Strength and Conditioning Research, 25: 2902-2910.

24. Wank, V., Frick, U. and Schmidtbleicher, D. 1998. Kinematics and electromyography of lower limb muscles in overground and treadmill running. International Journal of Sports Medicine, 19: 455-461.

\section{Figures and Table}

Figure 1. General view of the experimental sessions and run profile.

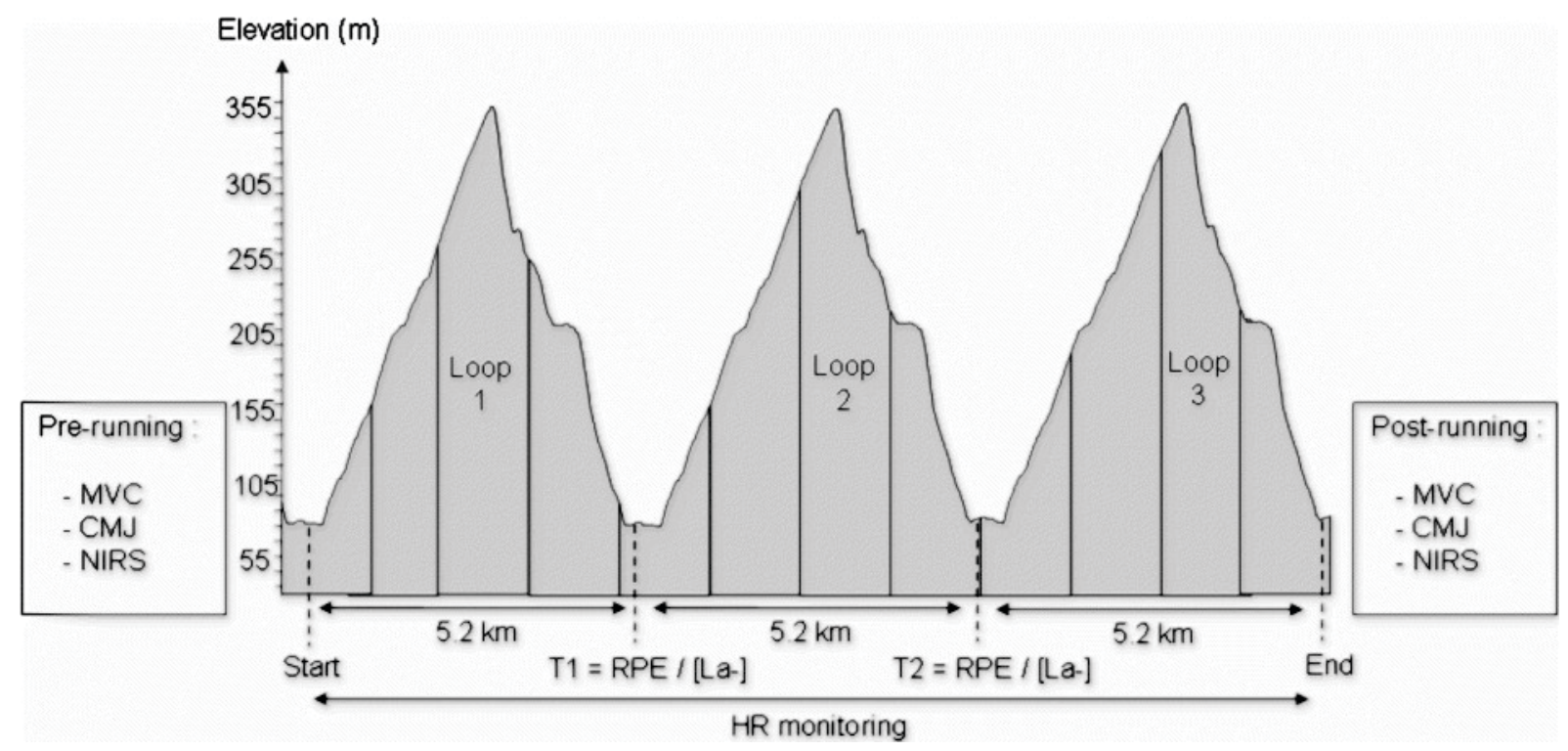

Figure 2. Variations in performance time within the three loops of CS and non-CS runs. ${ }^{*}$ indicates a significant difference to loop $1(P<0.05)$ for the CS and non-CS runs $(P<0.05)$.

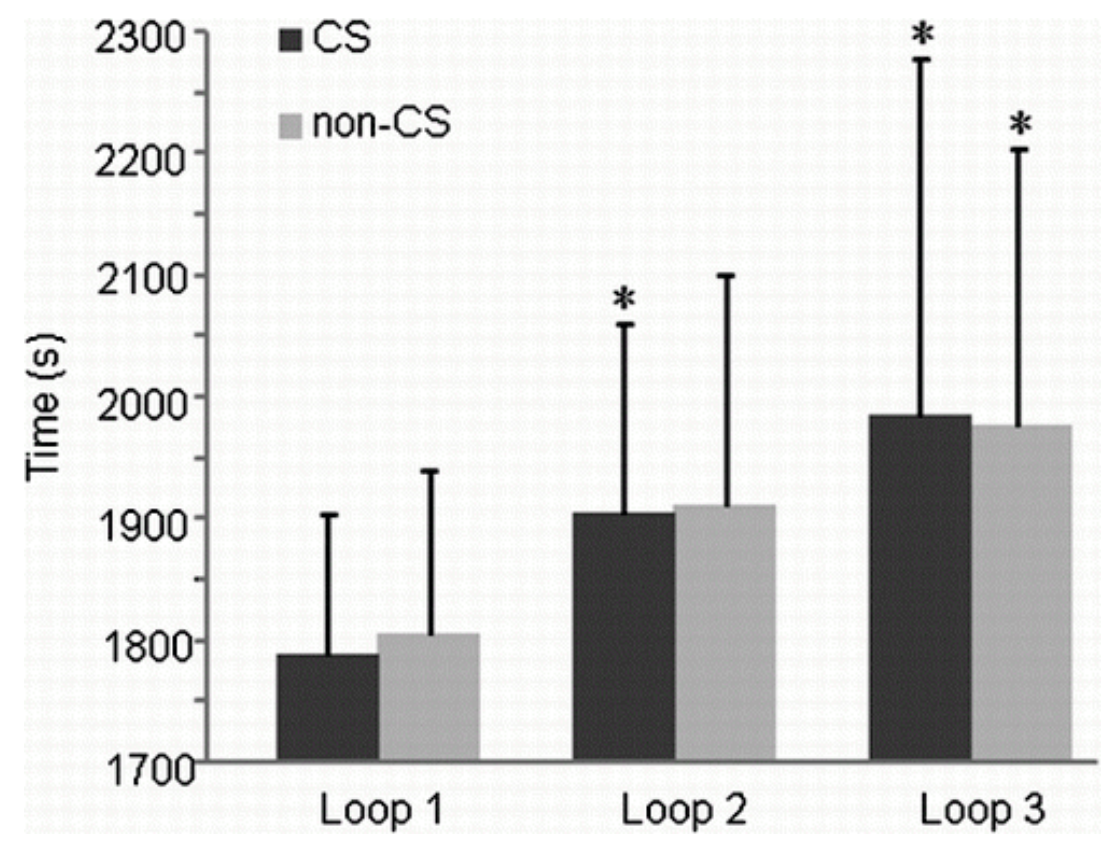


Figure 3. Variations in muscle oxygenation profile following the CS and non-CS runs. *indicates a significant difference in $\mathrm{mBF}$ and between the pre- and post-period for the CS and non-CS runs $(P<$ 0.05).

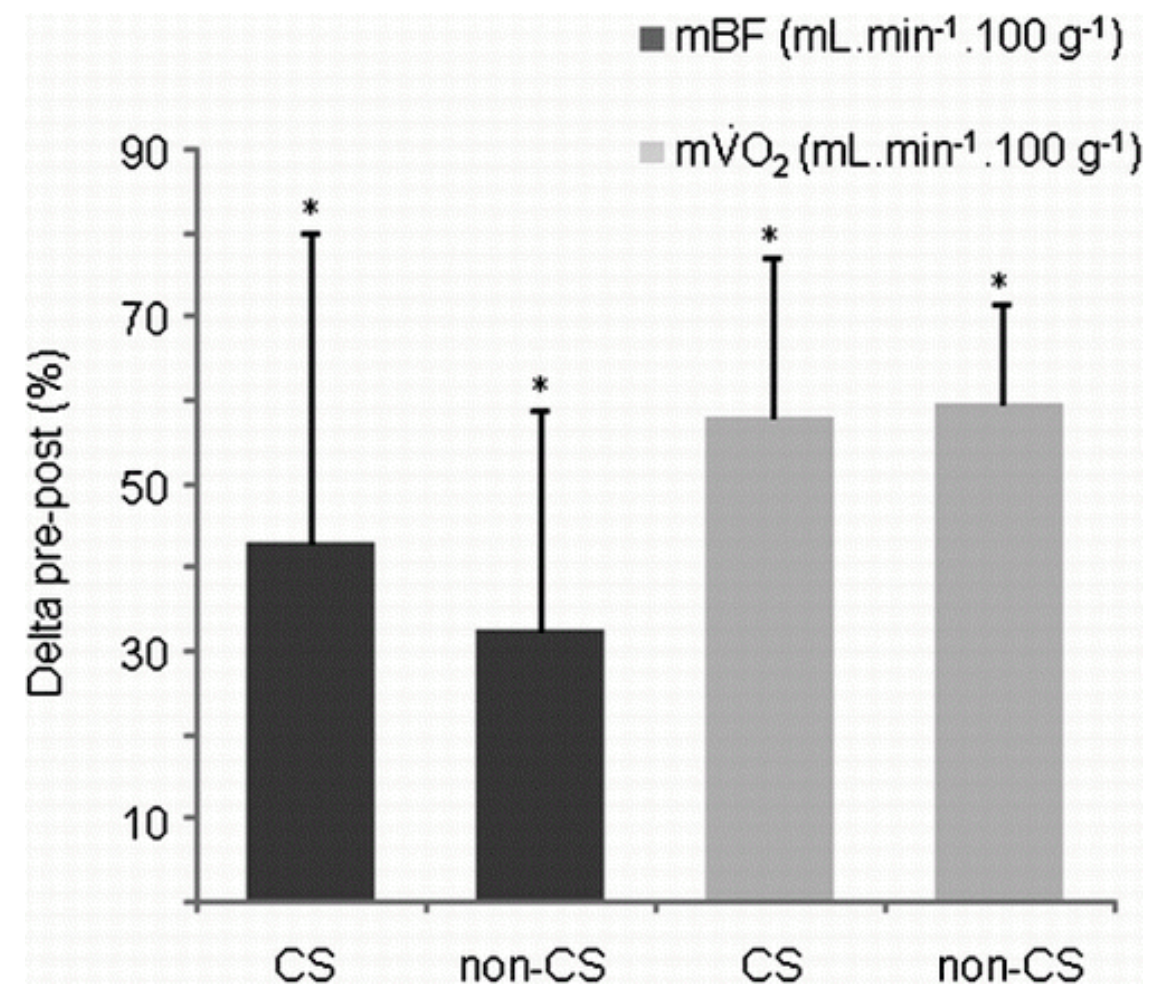

Table I. Variations in HR, [Bla $\left.{ }^{-}\right], \mathrm{RPE}_{\text {peripheral }}, \mathrm{RPE}_{\text {central }}$ and $\mathrm{RPE} \mathrm{E}_{\text {globlal }}$ values within the three loops of CS and non-CS runs. *indicates a significant difference with the loop \# 1 for the CS and non-CS runs $(P<0.05)$.

\begin{tabular}{|l|c|c|c|c|c|c|}
\hline & \multicolumn{2}{|c|}{ Loop 1 } & \multicolumn{2}{c|}{ Loop 2 } & \multicolumn{2}{c|}{ Loop 3 } \\
\hline & CS & Non-CS & CS & Non-CS & CS & Non-CS \\
\hline $\begin{array}{l}\text { HR (beats } \\
\left.\text { mitr }^{-1}\right)\end{array}$ & $166 \pm 11$ & $167 \pm 9$ & $168 \pm 12$ & $166 \pm 19$ & $169 \pm 12$ & $165 \pm 121$ \\
\hline $\begin{array}{l}\text { Blood lactate } \\
{\left[\text { Bla }^{-}\right]}\end{array}$ & $4.19 \pm 1.39$ & $3.75 \pm 1.90$ & $5.47 \pm 2.65$ & $4.72 \pm 2.24$ & $4.70 \pm 1.66$ & $5.07 \pm 1.71$ \\
\hline RPE peripheral & $12.7 \pm 2.2$ & $13.1 \pm 2.3$ & $14.2 \pm 1.8$ & $14.8 \pm 2.0$ & $15.8 \pm 2.5^{*}$ & $16.1 \pm 2.4^{*}$ \\
\hline RPE central & $13.2 \pm 1.9$ & $13.2 \pm 2.5$ & $15.3 \pm 1.6$ & $14.8 \pm 2.0$ & $16.1 \pm 2.3^{*}$ & $17.0 \pm 1.8^{*}$ \\
\hline RPE global & $13.9 \pm 1.7$ & $13.6 \pm 1.6$ & $15.6 \pm 1.9$ & $15.5 \pm 1.4$ & $17.1 \pm 2.5^{*}$ & $17.5 \pm 1.6^{*}$ \\
\hline
\end{tabular}

